\title{
Relationship of Early Vitamin D Concentrations and Gestational Diabetes Mellitus in Indian Pregnant Women
}

\author{
Pratibha Dwarkanath ${ }^{1 *}$, Vinotha Ponnusamy ${ }^{2}$, Tinku Thomas ${ }^{2}$, Siji Joseph ${ }^{3}$, \\ Annamma Thomas ${ }^{4}$, George Shirley ${ }^{4}$, C. N. Sheela ${ }^{4}$, Saurabh Mehta ${ }^{5}$ and \\ Anura V. Kurpad ${ }^{6}$
}

${ }^{1}$ Division of Nutrition, St. John's Research Institute, Bangalore, India, ${ }^{2}$ Department of Biostatistics, St. John's Research Institute \& Medical College, Bangalore, India, ${ }^{3}$ Agilent Technologies, Global Solution Development Center, Singapore, Singapore, ${ }^{4}$ Department of Obstetrics and Gynaecology, St. John's Medical College Hospital, Bangalore, India, ${ }^{5}$ Division of Nutritional Sciences, Cornell University, Ithaca, NY, United States, ${ }^{6}$ Department of Physiology \& Nutrition, St. John's Medical College \& St. John's Research Institute, Bangalore, India

Background: A high prevalence of vitamin D deficiency exists in pregnant Indian women ( 90\%). Increasing evidence suggests that vitamin D could play a pivotal role in maintaining normal glucose homeostasis. We aimed to determine the association between maternal vitamin D concentrations in early pregnancy and the risk of gestational diabetes mellitus (GDM).

Methods: A prospective observational study was conducted on healthy pregnant women $(n=392)$ attending routine antenatal care at St. John's Medical College Hospital, Bangalore recruited at $\sim 12$ weeks of gestation. At baseline, details on socio-economic status, obstetric history, dietary intakes, and anthropometry were collected. Venous plasma total vitamin D concentration was assessed using tandem liquid chromatography mass spectrophotometry (LC-MS/MS). Oral glucose tolerance test (OGTT) at recruitment, followed by glucose tolerance test (GTT) at mid-pregnancy was conducted. GDM was diagnosed and confirmed using the International Association of Diabetes and Pregnancy Study Groups (IADPSG) classification. Univariate and adjusted logistic regression models were used to evaluate the associations between total vitamin D concentrations at enrollment with GDM.

Results: Of the cohort, 10.2\% were diagnosed as GDM. Women with GDM were older (26 vs. 24 years) and heavier ( 51.6 vs. $51.2 \mathrm{~kg}$ ) compared to the rest. A higher prevalence of GDM was observed among women with 1st trimester plasma total vitamin $D$ in the lowest quartile ( $\leq 23.6 \mathrm{nmol} / \mathrm{L}$ ) compared to the subjects in the other three quartiles (16.1 vs. $8.6 \%, p=0.033$ ). Adjusted multivariable regression analysis showed that women in the lowest quartile of plasma total vitamin $D$ had twice the odds of GDM compared to women belonging to the remaining quartiles [OR $=2.32$ (95\% $\mathrm{Cl}: 1.10,4.91), p=0.028$ ].

Conclusions: Low plasma total vitamin $D$ concentrations in early pregnancy may be associated with a higher risk of GDM.

Keywords: plasma total vitamin D concentration, early pregnancy, glucose tolerance test (GTT), liquid chromatography mass spectrophotometry, gestational diabetes mellitus (GDM) 


\section{INTRODUCTION}

Gestational Diabetes Mellitus (GDM) is considered as an early marker of glucose intolerance, associated with both insulin resistance and impaired insulin secretion (1) and an increased risk of maternal and fetal complications during pregnancy. Infants of mothers with GDM may have complications at birth such as macrosomia, birth trauma, respiratory distress syndrome, jaundice, and hypoglycemia (2), an increased rate of primary cesarean section (3), preterm labor, fetal growth retardation, and neonatal hypocalcemia (4). With reference to the fetal origins of adult diseases, infants of mothers with GDM are at a higher risk of obesity and diabetes in later life compared to their unexposed siblings (5). In addition, GDM is also related with a high risk of the development of diabetes in these women $(6,7)$.

Several studies, either observational, prospective or nested case-control designs, have shown associations between maternal serum vitamin $\mathrm{D}$ concentrations in the 1st or early 2 nd trimester and the development of GDM after the 2nd trimester (810). These findings were supported by a meta-analysis of observational studies that indicated a consistent association between vitamin $\mathrm{D}$ deficiency and an increased risk of maternal GDM (11). Equally, there are also studies that have shown no associations between plasma vitamin D levels at early pregnancy and GDM (12), impaired fetal growth or altered neonatal cord plasma insulin secretory profile (13).

Given the high prevalence of vitamin D (70-100\%) deficiency in developing countries, especially in Indian pregnant women $(14,15)$, and evidence that vitamin $\mathrm{D}$ supplementation in gestational diabetes patients had beneficial effects on fasting plasma glucose and serum insulin levels $(16,17)$, it is important to evaluate the association of GDM with this condition of high vitamin D deficiency in these countries. Therefore, this study, was conducted in an ongoing prospective observational cohort of well-characterized healthy pregnant women to examine the relationship between 1st trimester vitamin D levels and GDM status during pregnancy.

\section{METHODS}

This study was part of an ongoing prospective observational cohort study of pregnant women conducted at St. John's Medical College Hospital (SJMCH), Bangalore, India. The detailed methodology and objectives of the cohort have been previously published (18). Pregnant women aged 17 to 41 years registering for antenatal screening in their first trimester between 2008 and 2014 were included in the study. Women with multiple fetuses (e.g., twins, triplets); women clinically diagnosed with a chronic illness (diabetes mellitus, hypertension, cardiac disease, or thyroid disease); tested positive for hepatitis B surface antigen (HbSAg), HIV or syphilis [venereal disease research laboratory test (VDRL)] infections; those on medications or with assisted pregnancy; and those planning to move outside the study city prior to delivery were excluded from the study. A convenient sampling method was used to select the study participants. Four hundred and nineteen subjects had their venous blood sample collected at recruitment and cord blood at delivery. Of these, a total of 392 subjects had their oral glucose tolerance test performed at recruitment; a screening test for GDM and then completed a glucose tolerance test (GTT) at mid-pregnancy to confirm the GDM status using International Association of Diabetes and Pregnancy Study Groups (IADPSG) classification of GDM (19) (Figures 1A,B). The Institutional Ethical Review Board of St. John's Medical College approved all study procedures and a written and signed consent was obtained from each study participant at enrollment.

At recruitment, socio-demographic information such as age, obstetric history, familial composition and socio-economic status (SES) was collected through a structured questionnaire. Maternal education was used as a surrogate marker of SES since the family income was not expected to be revealed correctly. The gestational age (in weeks) was calculated from the last date of the menstrual cycle and confirmed through ultrasonographic measurements (GE Voluson 730 Expert, probe 4C-A, CA, USA) within 2 weeks of enrollment. A validated FFQ [against 24-h food recalls that were obtained 3 times during each trimester of pregnancy in 154 subjects (20)] was administered at enrollment to obtain information on the habitual dietary intake for the preceding 3 months. The physical activity questionnaire during pregnancy (21) was administered at recruitment and the physical activity data (for $24 \mathrm{~h}$ ) was expressed as the duration (minutes/day), or as the product of the intensity (PAR) and duration (PARmin). A composite measure of daily physical activity, the physical activity level (PAL), was also calculated, as the ratio of the total energy expenditure (TEE; kJ/day) and the basal metabolic rate (BMR; kJ/day).

A digital weighing balance (Soehnle, Reutlingen, Germany) was used to record maternal weight to the nearest 100 grams during each antenatal visit. Height was measured with a stadiometer to the nearest 0.1 centimeter and maternal midupper arm circumference (MUAC; $\mathrm{cm}$ ) was measured using a plastic tape. Prediction equations were used to calculate body composition measures such as fat mass, fat-free mass and fat percentage (22) from the skinfold thicknesses measured at three sites (biceps, triceps and subscapular) to the nearest $0.2 \mathrm{~mm}$ using skinfold Holtain calipers (Holtain, Limited, Crosswell, Wales, UK) at recruitment. Body mass index (BMI) for mothers was calculated as weight in kilograms divided by height in meters squared $\left(\mathrm{kg} / \mathrm{m}^{2}\right)$.

Venous whole blood samples were collected into ethylenediaminetetraacetic acid (EDTA) and plain vacutainers (Becton Dickenson, NJ, USA) by a phlebotomist. Blood Hemoglobin concentration was measured using an automated cyanmethaemoglobin technique (ABX Pentra $60 \mathrm{C}+$, Horiba ABX diagnostics, Darmstadt, Germany). Vitamin D concentrations were measured by Liquid chromatography mass spectrometry (LC-MS/MS, 6460 Triple Quadrupole, Agilent Technologies, CA, USA) in maternal plasma samples at enrollment and in cord blood plasma at delivery. Samples were deproteinized by protein crash method and loaded onto a C18 Guard column (Zorbax Eclipse Plus $2.1 \times 12.5 \mathrm{~mm}, 5 \mu \mathrm{m}$, Agilent technologies) to trap the analytes of interest and directed to an analytical column (Poroshell 120 EC-C18, $2.1 \times 50 \mathrm{~mm}$, $2.7 \mu \mathrm{m}$, Agilent Technologies) maintained at $50^{\circ} \mathrm{C}$ for further 

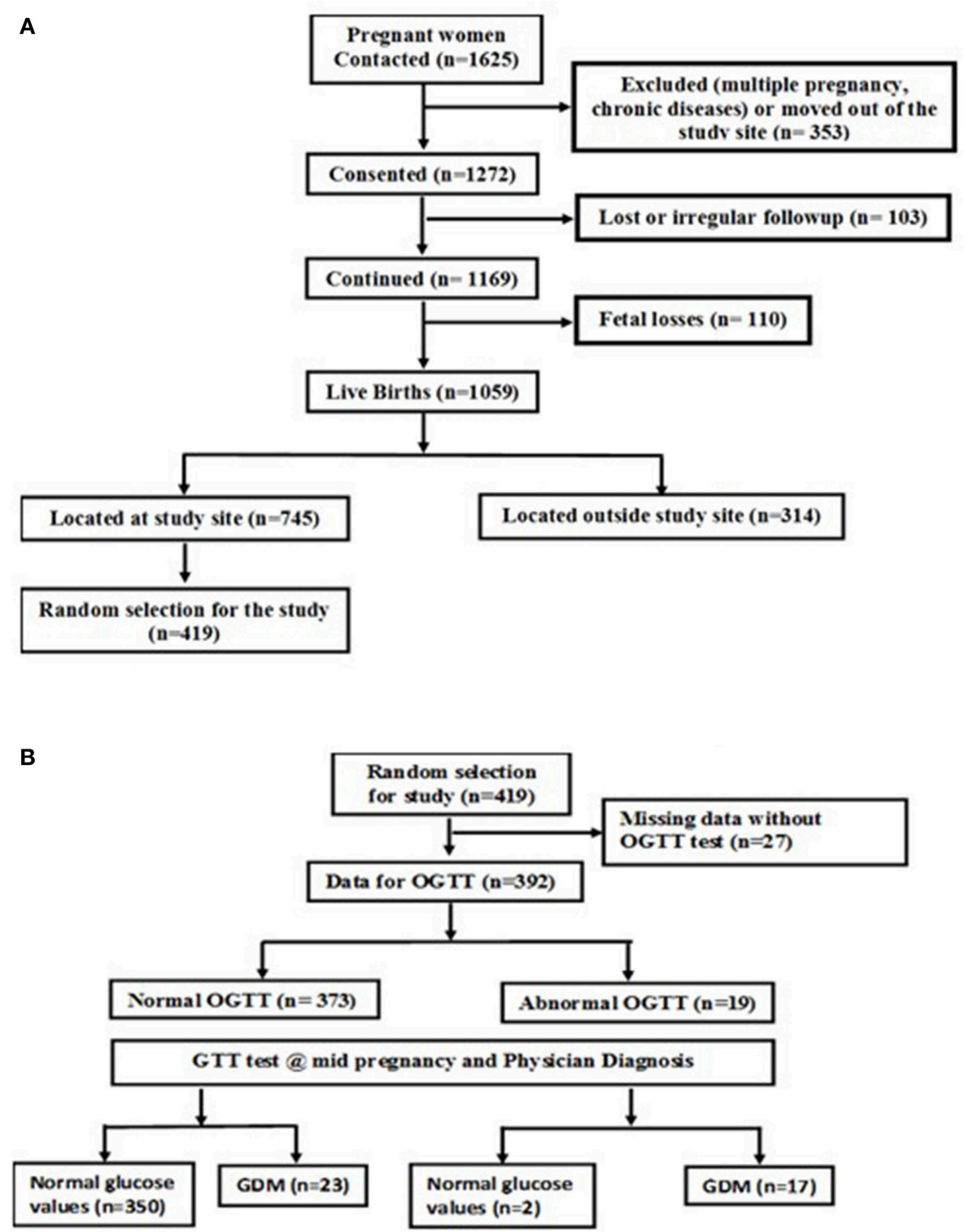

FIGURE 1 | (A) Flow chart of study subjects. (B) Flow chart of the subjects with GDM and normal glucose levels.

separation. MS was operated in Multiple Reaction Monitoring (MRM) mode for specific transitions of vitamin D2 [25(OH)D2] and vitamin D3 [25(OH)D3], along with a deuterated 25(OH)D3 as an internal standard, for relative quantification of vitamin D2 and D3. Data acquisition and analysis was performed by Mass Hunter Workstation (Version: B.05.01) software (Agilent Technologies, CA, USA). The coefficient of variation of the assay was $1.6 \%$.

The OGTT, a screening test for diabetes mellitus was performed during the 1st antenatal visit within the end of 1st trimester. After an approximate $8 \mathrm{~h}$ overnight fast, the subject consumed $75 \mathrm{~g}$ anhydrous glucose and, after $2 \mathrm{~h}$, a 2-ml venous blood sample was collected in EDTA vacutainer. The blood glucose was estimated by Hexokinase method using Dimensions
EXL with LM (Siemens Health Care Diagnostic Ltd) automated analyzer. GTT was performed during mid-pregnancy (between 24 and 28 weeks of gestation) to confirm the GDM status. A fasting blood sample was collected, glucose was consumed and blood samples post-dose, 1 and $2 \mathrm{~h}$ apart was collected. GDM was defined using International Association of Diabetes and Pregnancy Study Groups (IADPSG) criteria (19).

\section{Statistical Analysis}

In this study, mothers with vitamin $\mathrm{D}<30 \mathrm{nmol} / \mathrm{L}$ were categorized as having severe vitamin $\mathrm{D}$ deficiency, women with $<50 \mathrm{nmol} / \mathrm{L}$ as deficiency and insufficiency as $<75 \mathrm{nmol} / \mathrm{L}$ $(23,24)$. As plasma vitamin $\mathrm{D}$ concentrations were insufficient in $\sim 97 \%$ of mothers, tertiles were generated based on the 
TABLE 1 | Baseline characteristics of study subjects.

\begin{tabular}{|c|c|c|c|c|}
\hline Parameters & All data $(n=392)$ & $\begin{array}{l}\text { Women with gestational diabetes } \\
\text { mellitus }(n=40)\end{array}$ & $\begin{array}{c}\text { Women with normal } \\
\text { glucose levels }(n=352)\end{array}$ & $P$-value \\
\hline \multicolumn{5}{|c|}{ SOCIO-DEMOGRAPHIC CHARACTERISTICS } \\
\hline Age $(\text { years })^{\mp}$ & $23.9 \pm 3.8$ & $25.7 \pm 4.0$ & $23.7 \pm 3.7$ & 0.002 \\
\hline \multicolumn{5}{|l|}{ Education } \\
\hline Upto high school & $114(29.1)$ & $09(22.5)$ & $105(29.8)$ & 0.574 \\
\hline Diploma / PUC & $135(34.4)$ & $14(35.0)$ & $121(34.4)$ & \\
\hline University and above Parity & $143(36.5)$ & $17(42.5)$ & $126(35.8)$ & \\
\hline Nulliparous & $223(56.9)$ & $21(52.5)$ & $202(57.4)$ & 0.335 \\
\hline Multiparous & $169(43.1)$ & $19(47.5)$ & $150(42.6)$ & \\
\hline \multicolumn{5}{|c|}{ ANTHROPOMETRIC CHARACTERISTICS } \\
\hline LMP (weeks)Ғ & $12.0 \pm 2.0$ & $11.5 \pm 2.0$ & $11.4 \pm 2.3$ & 0.916 \\
\hline Height $(\mathrm{cm})^{\mp}$ & $156.1 \pm 5.7$ & $156.3 \pm 6.6$ & $156.1 \pm 5.6$ & 0.851 \\
\hline Weight $(\mathrm{kg})^{\mp}$ & $51.7 \pm 9.0$ & $51.6 \pm 9.0$ & $51.2 \pm 8.5$ & 0.005 \\
\hline BMl $\left(\mathrm{kg} / \mathrm{m}^{2}\right)^{\mp}$ & $21.2 \pm 3.4$ & $22.6 \pm 3.9$ & $21.0 \pm 3.3$ & 0.006 \\
\hline \multicolumn{5}{|l|}{ BMl categories } \\
\hline$<18.5$ & $90(23.0)$ & $8(20.0)$ & $82(23.4)$ & \\
\hline $18.5-24.9$ & $240(61.2)$ & $18(45.0)$ & $222(63.4)$ & 0.002 \\
\hline $25.0-29.9$ & $55(14.0)$ & $12(30.0)$ & $43(12.3)$ & \\
\hline$>30$ & $5(1.3)$ & $2(5.0)$ & $3(0.9)$ & \\
\hline Fat percent ${ }^{\mp}$ & $28.7 \pm 5.3$ & $30.7 \pm 5.8$ & $28.4 \pm 5.2$ & 0.012 \\
\hline Fat mass $(\mathrm{kg})^{\mp}$ & $15.2 \pm 5.1$ & $17.5 \pm 6.4$ & $14.9 \pm 4.8$ & 0.002 \\
\hline Fat free mass $(\mathrm{kg})^{\mp}$ & $36.5 \pm 4.9$ & $37.9 \pm 6.3$ & $36.3 \pm 4.6$ & 0.044 \\
\hline \multicolumn{5}{|l|}{ DIETARY INTAKES $\mp$} \\
\hline Energy (kcal/d) & $1844 \pm 503$ & $1794 \pm 386$ & $1849 \pm 514$ & 0.509 \\
\hline Protein (g/d) & $53.1 \pm 16.0$ & $51.7 \pm 12.5$ & $53.3 \pm 16.4$ & 0.566 \\
\hline Fat $(g / d)$ & $48.9 \pm 17.8$ & $47.1 \pm 14.0$ & $49.1 \pm 18.2$ & 0.494 \\
\hline Carbohydrate (g/d) & $297.8 \pm 79.3$ & $290.7 \pm 66.1$ & $298.6 \pm 80.7$ & 0.557 \\
\hline Saturated fat (g/d) & $16.8 \pm 6.9$ & $16.8 \pm 6.5$ & $16.8 \pm 7.0$ & 0.976 \\
\hline \multicolumn{5}{|c|}{ ANTENATAL BIOCHEMICAL SCREENING PARAMETERS } \\
\hline Hemoglobin concentration $\mp$ & $11.9 \pm 1.3$ & $11.8 \pm 1.4$ & $11.9 \pm 1.3$ & 0.615 \\
\hline Anemia (Hb <11gm\%) & $79(20.2)$ & $10(25.0)$ & 69 (19.6) & 0.268 \\
\hline Screening glucose values (mg/dl) & $96(83,119)$ & $103(87,129.5)$ & $96(83,117)$ & 0.101 \\
\hline \multicolumn{5}{|c|}{ PHYSICAL ACTIVITY LEVEL (PAL) ${ }^{\mp}$} \\
\hline PAL & $1.45 \pm 0.14$ & $1.42 \pm 0.13$ & $1.45 \pm 0.15$ & 0.249 \\
\hline
\end{tabular}

Values represent number (percentages); “Ғ” indicates values as mean $\pm S D$.

vitamin D distribution in this population to evaluate GDM at each level. Data that were continuous were checked for normality using normal probability plots and values were indicated as mean and standard deviation if normally distributed, or otherwise as median and interquartile range. Sociodemographic characteristics, maternal anthropometry, physical activity levels, dietary intake, hemoglobin and vitamin $\mathrm{D}$ concentration were compared between women diagnosed with GDM and the women with normal glucose levels during pregnancy using the independent-samples $t$-test or $\chi^{2}$ test. A logistic regression model was constructed to find the association between vitamin D concentration at recruitment and GDM status; a binary variable of vitamin $\mathrm{D}$ concentration was constructed such that group 1 was with subjects belonging to the quartile 1 of vitamin $\mathrm{D}$ concentration and group 2 with subjects belonging to the 2nd, 3rd, and 4th quartiles. All potential confounders that were associated in unadjusted analysis with GDM status that included maternal sociodemographic, anthropometric variables measured at baseline, season at recruitment and vitamin D concentration with $P<0.10$ were considered in multiple variable logistic regression model. The multivariable analysis examined the association of maternal weight and BMI in separate models. Adjusted odds ratios (AOR) and 95\% confidence interval (95\% $\mathrm{CI})$ are reported and two-sided $P$-values $(P<0.05)$ were considered statistically significant. All analyses were carried out with the Statistical Package for Social Sciences (SPSS) program (version 18.0, SPSS, Chicago, IL, USA).

\section{RESULTS}

This study was conducted on a subset of pregnant women from the St. John's Pregnancy Cohort. Of the total 1625 pregnant 
TABLE 2 | Percentage of women with GDM and normal glucose levels across vitamin D status at recruitment.

\begin{tabular}{lccc}
\hline Parameters & $\begin{array}{c}\text { Women with } \\
\text { gestational } \\
\text { diabetes } \\
\text { Mellitus } \\
(\boldsymbol{n}=\mathbf{4 0})\end{array}$ & $\begin{array}{c}\text { Women with } \\
\text { normal } \\
\text { glucose levels } \\
(\boldsymbol{n}=\mathbf{3 5 2})\end{array}$ & P-value \\
\hline $\begin{array}{l}\text { Vit D levels (nmol/L) } ¥ \\
\text { Vit D insufficiency }(<75.0\end{array}$ & $34.0 \pm 17.4$ & $37.5 \pm 19.2$ & 0.264 \\
$\mathrm{nmol} / \mathrm{L})$ & $40(100)$ & $333(96.5)$ & 0.263 \\
$\begin{array}{l}\text { Vit D deficiency }(<50.0 \\
\mathrm{nmol} / \mathrm{L})\end{array}$ & $34(85.0)$ & $279(80.9)$ & 0.349 \\
$\begin{array}{l}\text { Vit D severe deficiency } \\
(<30.0 \text { nmol/L) }\end{array}$ & $20(50.0)$ & $120(34.8)$ & 0.058 \\
\end{tabular}

Values represent number (percentages); ${ }^{¥}$ indicates values as mean $\pm S D$.

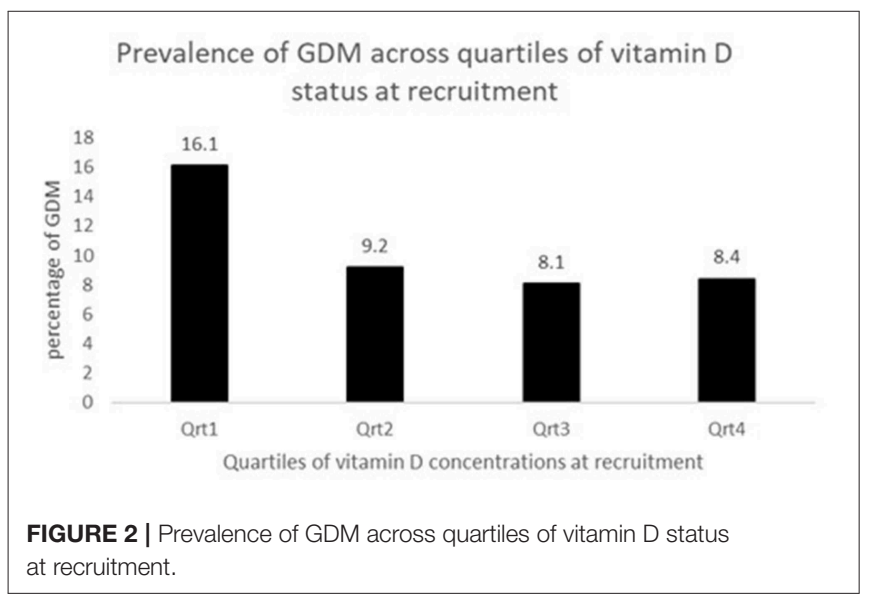

women contacted in this cohort, a sub-set of 392 subjects were randomly selected for this study (Figure 1A). The subjects included in this analysis were those who were screened for oral glucose tolerance test (OGTT) at recruitment within the 1 st trimester of pregnancy $(n=392)$ and a follow up glucose tolerance test (GTT) at mid pregnancy was performed. The GTT at mid pregnancy showed that $40(10.2 \%)$ pregnant women had GDM (Figure 1B). The baseline characteristics at recruitment for the women diagnosed with GDM and those with normal plasma glucose is shown in Table 1. The GDM women were significantly older (26 vs. 24 years), heavier (51.6 vs. $51.2 \mathrm{~kg}$ ) and almost $35 \%$ of them belonged to the overweight and obese category of BMI $>25.0 \mathrm{~kg} / \mathrm{m}^{2}$, compared to $13.2 \%$ of women with normal glucose level (all $p<0.05$ ). Similarly, at baseline, the GDM women had significantly different body composition parameters such as percent fat, fat mass and fat free mass (30.7 vs. $28.4 \% ; 17.5$ vs. $14.9 \mathrm{~kg} ; 37.9$ vs. $36.3 \mathrm{~kg}$ ), respectively. There were no significant differences in dietary intake at baseline between mothers with GDM and those with normal glucose levels. There were no differences in the mean hemoglobin concentration and equal numbers of women were anemics in both the groups at recruitment.

The concentration of plasma vitamin D2 was negligible in all subjects, and therefore only the total plasma vitamin $\mathrm{D}$ concentrations are reported. There was a high proportion of vitamin D deficiency and insufficiency. Overall, $81.5 \%$ of mothers were vitamin $\mathrm{D}$ insufficient and $37.2 \%$ were severe vitamin $\mathrm{D}$ deficient. There was a negative non-significant correlation between the vitamin D concentration and GTT glucose values; for fasting glucose $(r=-0.081, P=0.330)$, at $1 \mathrm{~h}(r=-0.036$, $P=0.697)$ and at $2 \mathrm{~h}(r=-0.016, P=0.857)$, respectively. The study participants were divided into groups based on the cutoffs of vitamin D levels. The proportion of mothers with GDM was compared between women with vitamin D severe deficiency $(<30 \mathrm{nmol} / \mathrm{L})$ and women without vitamin $\mathrm{D}$ severe deficiency ( $\geq 30 \mathrm{nmol} / \mathrm{L}$ ). It was observed that the percentage of GDM's were significantly higher in women with vitamin $\mathrm{D}$ deficiency ( 14.3 vs. $8.2 \%$; $P=0.044$ ). Similar analysis was performed using the vitamin $\mathrm{D}$ cut-off's of $75 \mathrm{nmol} / \mathrm{L}$ to categorize the women as sufficiency/insufficiency groups. There was no significant difference in the percentage of GDM's in the women with vitamin $\mathrm{D}$ insufficiency $(<75 \mathrm{nmol} / \mathrm{L})$ and women without vitamin $\mathrm{D}$ insufficiency $(\geq 75 \mathrm{nmol} / \mathrm{L})(10.8$ vs. $8.3 \%, P=0.349)$, respectively. Plasma vitamin $\mathrm{D}$ concentrations at baseline among women who developed GDM did not differ significantly from those who remained normoglycemic (mean 34.0 vs. $37.5 \mathrm{nmol} / \mathrm{L}$ ). However, the group that had plasma vitamin D concentrations $<30.0 \mathrm{nmol} / \mathrm{L}$ had a higher proportion of mothers with GDM compared to those with concentrations $\geq 30.0 \mathrm{nmol} / \mathrm{L}(50.0$ vs. $34.8 \%, P=0.058$, Table 2 ). When considered as quartiles, the lowest quartile $(\leq 23.6 \mathrm{nmol} / \mathrm{L})$ of vitamin $\mathrm{D}$ concentration at recruitment had a significantly higher proportion of GDM compared to the those in the higher quartiles of vitamin D $(16.1 \%$ GDM in the lowest quartile vs. 9.2 in the 2 nd quartile, 8.1 in the 3 rd quartile and 8.4 in the highest quartile of plasma vitamin D concentrations, $P=0.040$, Figure 2).

Due to the small sample size, the subjects in the $2 \mathrm{nd}, 3 \mathrm{rd}$ and 4th quartiles of plasma vitamin $\mathrm{D}$ concentrations were combined to allow for a binary grouping for further analysis $(\leq 23.6 \mathrm{nmol} / \mathrm{L}$ vs. $>23.6 \mathrm{nmol} / \mathrm{L}$ ). The odds ratio of GDM in the lowest quartile of plasma vitamin D concentration was 2.05 (95\% CI: 1.03, 4.09; $P=0.040)$ compared to the other quartiles (combined). The AOR for GDM was 2.27 (95\% CI: $1.08,4.78$; $P=0.031)$ in the lowest quartile of plasma vitamin $\mathrm{D}$ concentration in a model adjusting for maternal age, education, parity, BMI and physical activity levels at recruitment). The AOR was 2.32 (95\% CI: 1.10, 4.91; $P=0.028$ ) when maternal BMI was replaced with weight at recruitment. Similarly, the AOR was 2.17 (95\% CI:1.03, 4.56; $P=0.041)$ when maternal BMI and body weight was replaced with percent body fat (Table 3 ).

\section{DISCUSSION}

In the present study, $10.2 \%$ of the women were diagnosed with GDM during pregnancy. The prevalence of GDM in India has been reported to vary from 3.8 to $21 \%$ across the country, with higher rates in urban compared to rural populations (25-27). While various factors such as primipara mothers with age $>30$ years, women with a family history of diabetes mellitus, maternal obesity, history of macrosomia, and glycosuria have been shown 
TABLE 3 | Association of vitamin D concertation at recruitment and GDM during pregnancy.

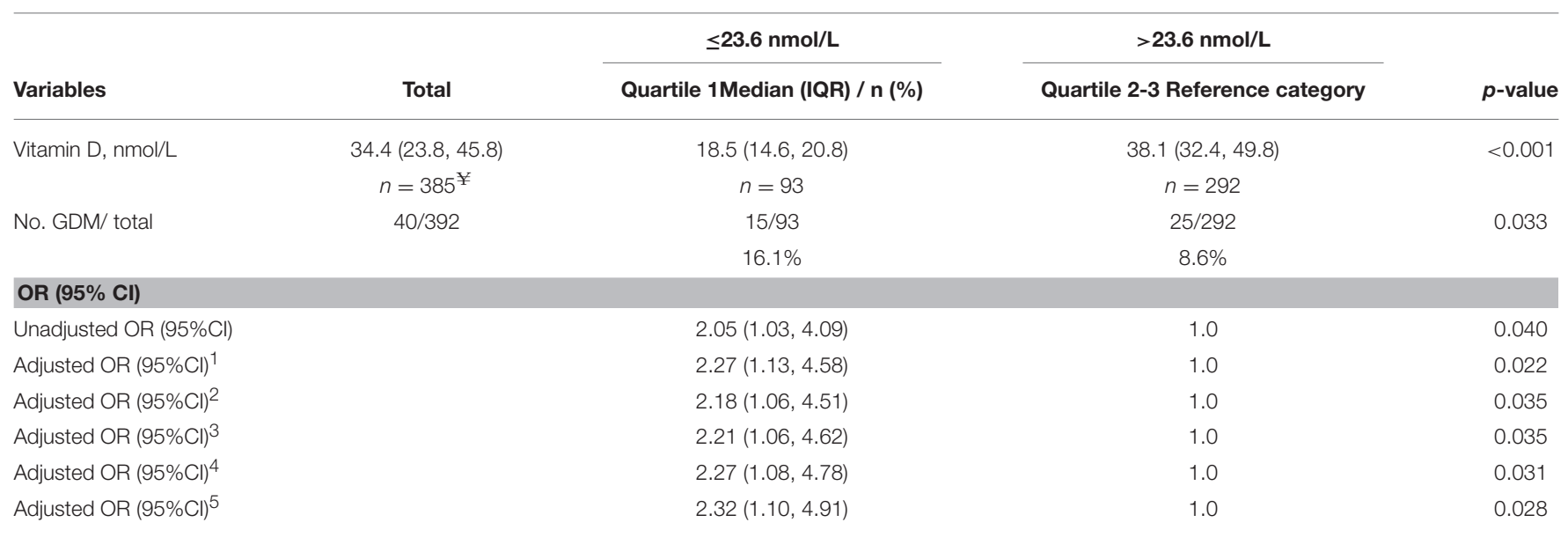

"GDM, Gestational Diabetes Mellitus defined as per the IADPSG classification; $¥ 7$ subjects had vitamin D missing values.

" $p$-value" from trend test across the lowest vs. the remaining quartiles.

${ }^{1}$ Adjusted odds ratio From a logistic regression model containing seasonality.

${ }^{2}$ Adjusted odds ratio from a logistic regression model controlling for seasonality and socio-demographic characteristics (maternal age, education categories, parity categories).

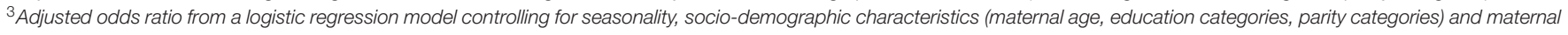
$B M l$ at recruitment.

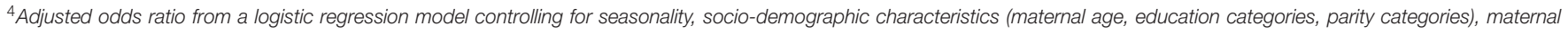
$B M I$ and physical activity level at recruitment.

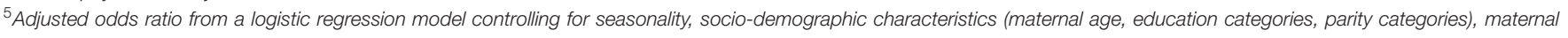
body weight and physical activity level at recruitment.

to be associated with an increased risk of GDM, we have found that plasma vitamin $\mathrm{D}$ concentrations at the 1st trimester of pregnancy were lower in those women who developed GDM.

In our study, $81.5 \%$ of the women had plasma vitamin $\mathrm{D}$ concentrations that would classify them to be "insufficient" and about $50 \%$ of the women diagnosed to have GDM had vitamin D concentrations $<30 \mathrm{nmol} / \mathrm{L}$.

Our findings of the association of low maternal plasma vitamin $\mathrm{D}$ concentrations in early pregnancy with an increased risk for GDM is consistent with findings from three separate meta-analyses of published studies $(11,28,29)$, emphasizing the pivotal role of vitamin $\mathrm{D}$ in the perinatal period. This association remained statistically significant even after adjusting for the confounding factors which is in accordance with recent metaanalysis conducted by $\mathrm{Hu}$ et al indicating a decrease in the levels of vitamin D in GDM mothers as compared to the control group (30). An increase in the risk of GDM, by $40-60 \%$, in women with vitamin $\mathrm{D}$ deficiency during the 2 nd trimester of pregnancy $(28,29,31)$ has also been previously demonstrated. Roth et al. also showed a potentially beneficial role for vitamin D in reducing the risk of GDM (RR: 0.61, 95\%CI 0.34-0.83) in 2,643 pregnant women (32). Cross sectional studies at mid-pregnancy (24-28 weeks of gestation) conducted by Clifton-Bligh et al. demonstrated a poor vitamin D status as the risk factor for poor glucose control (33). The current study showed a negative nonsignificant correlation between the vitamin $\mathrm{D}$ concentration and GTT values (fasting glucose, at 1 and $2 \mathrm{~h}$ ) which is in alignment with the findings of Maghbooli et al. confirming the association of poor vitamin D status and the risk of GDM through a negative correlation between serum vitamin $\mathrm{D}$ and fasting plasma glucose, fasting insulin, and insulin resistance (calculated by HOMA-IR)
(34). Similarly, the association between serum vitamin D and glycated hemoglobin (HbA1c), an integrated measure of blood glucose control with GDM was also observed, albeit during the second half of pregnancy (35). In contrast, findings of a null relationship between maternal plasma vitamin $\mathrm{D}$ concentrations and risk of GDM also exist $(13,36,37)$. The inconsistent findings of the association between plasma vitamin $\mathrm{D}$ concentrations and the risk of developing GDM may be due to other factors, such as selection bias, timing and methodology of measuring plasma vitamin D concentrations, classification criteria for defining vitamin D deficiency or insufficiency $(24,38)$, time of GDM diagnosis and diagnostic criteria for $\operatorname{GDM}(39,40)$.

There are a number of proposed mechanisms for the association between low vitamin $\mathrm{D}$ concentrations and the risk of GDM. Vitamin D is thought to modulate pancreatic $\beta$-cell function and secretion by binding to its circulating active form of vitamin $\mathrm{D}$ with $\beta$-cell vitamin $\mathrm{D}$ receptor and regulating the balance between the extracellular and intracellular $\beta$-cell calcium pools (41). It has also been proposed that vitamin D can promote insulin sensitivity by stimulating the expression of insulin receptors and enhancing insulin responsiveness for glucose transport (1). Since vitamin D is also known to regulate extracellular calcium, low vitamin D levels may lead to inadequate intracellular cytosolic calcium, which is required for the insulin-mediated intracellular processes and glucose regulation (42).

There are many factors that could confound the relation between early pregnancy vitamin D status and GDM. Body weight is one such factor. Analysis of the National Health and Nutrition Examination Survey (NHANES) for the years 2003/2004 demonstrated that vitamin D deficiencies were highly 
prevalent in overweight and obese American subjects (43). In our study, on replacing maternal body weight with BMI in the adjusted analysis, we found that the association between vitamin $\mathrm{D}$ concentration and GDM persisted indicating that the women with low vitamin D levels at recruitment had 2.27 times odds of having GDM. Another confounding factor might be seasonal variation (44). In this study, adjusting for the season at the time of recruitment did not change the significant association between vitamin D status and GDM.

In conclusion, maternal vitamin $\mathrm{D}$ deficiency in early pregnancy was significantly associated with an increased risk for GDM in South Indian pregnant women. The Indian population is diverse and variable, and the present study women may not be representative. The strength of this study was the analysis of maternal vitamin D status in the 1st trimester of pregnancy as a surrogate of pre-pregnancy state. However, we did not estimate plasma insulin and hemoglobin A1c (HbAlc) which is one of the limitations of the study. Further, well-designed intervention trials to investigate the effect of vitamin $\mathrm{D}$ interventions, aimed at improving maternal concentration before or during pregnancy, on birth outcomes are required.

\section{DATA AVAILABILITY}

The datasets generated for this study are available on request to the corresponding author.

\section{ETHICS STATEMENT}

This study was carried out in accordance with the guidelines and approved by the Ethical Committee

\section{REFERENCES}

1. Chiu KC, Chu A, Go VI, Saad MF. Hypovitaminosis D is associated with insulin resistance and beta cell dysfunction. Am J Clin Nutr. (2004) 79:820-5. doi: 10.1093/ajcn/79.5.820

2. Carrapato M. The offspring of gestational diabetes. J Perinat Med. (2003) 31:5-11. doi: 10.1515/JPM.2003.001

3. Gorgal R, Gonçalves E, Barros M, Namora G, Magalhães A, Rodrigues T, et al. Gestational diabetes mellitus: a risk factor for non-elective cesarean section. $J$ Obstet Gynaecol Res. (2012) 38:154-9. doi: 10.1111/j.1447-0756.2011.01659.x

4. Barrett H, McElduff A. Vitamin D and pregnancy: an old problem revisited. Best Pract Res Clin Endocr Metab. (2010) 24:527-39 doi: 10.1016/j.beem.2010.05.010

5. David J, Pettitt DJ, Aleck KA, Baird HR, Carraher MJ, Bennett PH, et al. Congenital susceptibility to NIDDM: Role of intrauterine environment. Diabetes. (1988) 37:622-8. doi: 10.2337/diabetes.37.5.622

6. Sivaraman SC, Vinnamala S, Jenkins D. Gestational Diabetes and Future Risk of Diabetes. J Clin Med Res. (2013) 5:92-96. doi: 10.4021/jocmr1201w

7. Javaid M, Crozier S, Harvey N, Gale C, Dennison E, Boucher B, et al. Maternal vitamin D status during pregnancy and childhood bone mass at age 9 years: a longitudinal study. Lancet. (2006) 367:36-43. doi: 10.1016/S0140-6736(06)67922-1

8. Park S, Yoon HK, Ryu HM, Han YJ, Lee SW, Park BK, et al. Maternal vitamin $\mathrm{D}$ deficiency in early pregnancy is not associated with gestational diabetes mellitus development or pregnancy outcomes in Korean pregnant women in a prospective study. J Nutr Sci Vitaminol. (2014) 60:269-75. doi: $10.3177 /$ jnsv. 60.269 of St. John's Medical College Hospital. All subjects gave written informed consent in accordance with the Declaration of Helsinki. The study protocol was approved by the St. John's Medical College Ethical Review Committee.

\section{AUTHOR CONTRIBUTIONS}

$\mathrm{PD}, \mathrm{SM}$, and AK took part in conceptualizing the study and writing the manuscript. PD, AT, GS, and CS were involved in data collection. PD, VP, TT, SM, and AK were involved in analyzing data and writing the manuscript. SJ was involved in his expert comments in vitamin D analysis. AK stands as guarantor of the study.

\section{FUNDING}

This study was supported by the Division of Nutritional Sciences, Cornell University, Ithaca, New York, US for the vitamin D analysis and Intramural funds from the Division of Nutrition, St. John's Research Institute to conduct the study.

\section{ACKNOWLEDGMENTS}

We greatly appreciate the assistance of Nancy Nanditha M, Roopashree C, Aruna B. S and Arogya Mary in data collection and Dr. Sarita Devi in the analysis of plasma vitamin D concentrations. We thank the pregnant women who participated in this study and the doctors and nurses who made this study possible.

9. Lacroix M, Battista MC, Doyon M, Houde G, Menard J, Ardilouze JL, et al. Lower vitamin D levels at first trimester are associated with higher risk of developing gestational diabetes mellitus. Acta Diabetol. (2014) 51:609-16. doi: 10.1007/s00592-014-0564-4

10. Zhang C, Qiu C, Hu FB, David RM, van Dam RM, Bralley A. Maternal plasma 25-hydroxyvitamin $\mathrm{D}$ concentrations and the risk for gestational diabetes mellitus. PLoS ONE. (2008) 3:e3752. doi: 10.1371/journal.pone.0003753

11. Zhang MX, Pan GT, Guo JF, Li BY, Qin LQ, Zhang ZL. Vitamin D deficiency increases the risk of gestational diabetes mellitus: a meta-analysis of observational studies. Nutrients. (2015) 7:8366-75. doi: 10.3390/nu7105398

12. Makgoba M, Nelson SM, Savvidou M, Messow CM, Nicolaides K, Sattar N. First-trimester circulating 25-hydroxyvitamin D levels and development of gestational diabetes mellitus. Diabetes Care. (2011) 34:1091-3 doi: $10.2337 / \mathrm{dc} 10-2264$

13. Farrant HJ, Krishnaveni GV, Hill JC, Boucher BJ, Fisher DJ, Noonan K, et al. Vitamin D insufficiency is common in Indian mothers but is not associated with gestational diabetes or variation in newborn size. Eur J Clin Nutr. (2009) 63:646-52. doi: 10.1038/ejcn.2008.14

14. Ritu G, Ajay G. Vitamin D deficiency in India: prevalence, causalities and interventions. Nutrients. (2014) 6:729-75. doi: 10.3390/nu6020729

15. Sachan A, Gupta R, Das V, Agarwal A, Awasthi PK, Bhatia V. High prevalence of vitamin D deficiency among pregnant women and their newborns in northern India. Am J Clin Nutr. (2005) 81:1060-4. doi: 10.1093/ajcn/81.5.1060

16. Shahgheibi S, Farhadifar F, Pouya B. The effect of vitamin D supplementation on gestational diabetes in high-risk women: Results from a randomized placebo-controlled trial. J Res Med Sci. (2016) 2016:21-2. doi: 10.4103/1735-1995.175148 
17. Jamilian M, Samimi M, Ebrahimi FA, et al. The effects of vitamin D and omega-3 fatty acid co-supplementation on glycemic control and lipid concentrations in patients with gestational diabetes. J Clin Lipidol. (2017) 11:459-68. doi: 10.1016/j.jacl.2017.01.011

18. Dwarkanath P, Barzilay JR, Thomas T, Thomas A, Bhat S, Kurpad AV. High folate and low vitamin B-12 intakes during pregnancy are associated with small-for-gestational age infants in South Indian women: a prospective observational cohort study. Am J Clin Nutr. (2013) 98:1450-8. doi: 10.3945/ajcn.112.056382

19. Metzger BE. International association of diabetes and pregnancy study group consensus panel. International association of diabetes and pregnancy study groups recommendations on the diagnosis and classification of hyperglycemia in pregnancy Diabetes Care. (2010) 33:676-82. doi: 10.2337/dc09-1848

20. Dwarkanath P, Soares MJ, Thomas T, Vaz M, Swaminathan S, Kurpad AV. Food frequency questionnaire is a valid tool for the assessment of dietary habits of South Indian pregnant women. Asia Pac J Public Health. (2014) 26:494-506. doi: 10.1177/1010539512459945

21. Dwarkanath P, Muthayya S, Vaz M, Thomas T, Mhaskar A, Mhaskar R, et al. The relationship between maternal physical activity during pregnancy and birth weight. Asia Pac J Clin Nutr. (2007) 16:704-10.

22. Durnin JVGA, Womersley J. Estimates of total body fat from skinfold thickness: measurements on 481 men and women aged from 16 to 72 years. Br J Nutr. (1974) 32:77-9. doi: 10.1079/BJN19740060

23. Holick MF. Vitamin D: evolutionary, physiological and health perspectives. Curr Drug Targets. (2011) 12:4-18. doi: 10.2174/138945011793591635

24. IOM Institute of Medicine (2011). Dietary Reference Intakes for Calcium and Vitamin D. Washington, DC (2011).

25. Seshiah V, Balaji V, Balaji MS, Panneerselvam A, Kapur A. Pregnancy and Diabetes Scenario around the World: India. Int J Gynaecol Obstet. (2009) 104:S35-8. doi: 10.1016/j.ijgo.2008.11.035

26. Seshiah V, Balaji V, Balaji MS, Panneerselvam A, Arthi T, Thamizharasi M, et al. Prevalence of GDM in South India (Tamil Nadu) - a community based study. JAPI. (2008) 56:329-33.

27. Grewal E, Kansra S, Khadgawat R, Kachhawa G, Ammini AC, Kriplani A, et al. Prevalence of GDM Among Women Attending a Tertiary Care Hospital AIIMS Presented at DIPSI 2009 and 5th DIP Symposium. (Sorrento) (2009).

28. Aghajafari F, Nagulesapillai T, Ronksley PE, Tough SC, O’Beirne M, Rabi DM. Association between maternal serum 25-hydroxyvitamin D Level and pregnancy and neonatal outcomes: systematic review and meta-analysis of observational studies. Br Med J. (2013) 346:f1169. doi: 10.1136/bmj.f1169

29. Wei SQ, Qi HP, Luo ZC, Fraser WD. Maternal vitamin D status and adverse pregnancy outcomes: a systematic review and meta-analysis. J Matern Fetal Neonatal Med. (2013) 26:889-99. doi: 10.3109/14767058.2013.765849

30. Hu L, Zhang Y, Wang X, et al. Maternal Vitamin D Status and risk of gestational diabetes: a meta-analysis. Cell Physiol Biochem. (2018) 45:291-300. doi: 10.1159/000486810

31. Poel YH, Hummel P, Lips P, Stam F, van der Ploeg T, Simsek S. Vitamin D and gestational diabetes: a systematic review and meta-analysis. Euro J Internal Med. (2012) 23:465-9. doi: 10.1016/j.ejim.2012.01.007

32. Roth DE, Leung M, Mesfin E, Qamar H, Watterworth J, Papp E. Vitamin D supplementation during pregnancy: state of the evidence from a systematic review of randomised trials. BMJ. (2017) 359:j5237. doi: 10.1136/bmj.j5237

33. Clifton-Bligh RJ, McElduff P, McElduff A. Maternal vitamin D deficiency, ethnicity and gestational diabetes. Diabet Med. (2008) 24:27-32. doi: 10.1111/j.1464-5491.2008.02422.x
34. Maghbooli Z, Hossein-Nezhad A, Karimi F, et al. Correlation between vitamin D3 deficiency and insulin resistance in pregnancy. Diabetes Metab Res Rev. (2008) 24:27-32. doi: 10.1002/dmrr.737

35. Lau SL, Gunton JE, Athayde NP, Byth K, Cheung NW. Serum 25-hydroxyvitamin D and glycated haemoglobin levels in women with gestational diabetes mellitus. Med J Aust. (2011) 194:334-7. doi: 10.5694/j.1326-5377.2011.tb03000.x

36. Harvey NC, Holroyd C, Ntani G, Javaid K, Cooper P, Moon R, et al. Vitamin D supplementation in pregnancy: a systematic review. Health Technol Assess. (2014) 18:1-190. doi: 10.3310/hta18450

37. De-Regil LM, Palacios C, Lombardo LK, Peña-Rosas JP. Vitamin D supplementation for women during pregnancy. Cochrane Database Syst Rev. (2016) 14:CD008873. doi: 10.1002/14651858.CD0088 73.pub3

38. Alshahrani F, Aljohani M. Vitamin D: deficiency, sufficiency and toxicity. Nutrients. (2013) 5:3605-16. doi: 10.3390/nu50 93605

39. Joergensen JS, Lamont RF, Torloni MR. Vitamin D and gestational diabetes: an update. Curr Opin Clin Nutr Metab Care. (2014) 17:360-7. doi: 10.1097/MCO.0000000000000064

40. Mahalakshmi MM, Bhavadharini B, Maheswari K, Anjana RM, Jebarani S, Ninov L, et al. Current practices in the diagnosis and management of gestational diabetes mellitus in India (WINGS-5). Indian J Endocr Metab. (2016) 20:364-8. doi: 10.4103/2230-8210.180001

41. Norman AW, Frankel JB, Heldt AM, Grodsky GM. Vitamin D deficiency inhibits pancreatic secretion of insulin. Science. (1980) 209:823-5. doi: $10.1126 /$ science. 6250216

42. Draznin B, Sussman KE, Eckel RH, Kao M, Yost T, Sherman NA. Possible role of cytosolic free calcium concentrations in mediating insulin resistance of obesity and hyperinsulinemia. J Clin Invest. (1988) 82:1848-52. doi: 10.1172/JCI113801

43. Lithy AE, Abdella RM, El-Faissal YM, Sayed AM, Samie RMA. The relationship between low maternal serum vitamin $\mathrm{D}$ levels and glycemic control in gestational diabetes assessed by HbAlc levels: an observational cross-sectional study. BMC Pregn Childb. (2014) 14:362. doi: 10.1186/1471-2393-14-362

44. Haggarty P, Campbell D, Knox S, Horgan G, Hoad G, Boulton E, et al. Vitamin D in pregnancy at high latitude in Scotland. Br J Nutr. (2013) 109:898-905. doi: $10.1017 /$ S0007114512002255

Conflict of Interest Statement: SM is an unpaid board member for a diagnostic start up focused on measurement of nutritional biomarkers at the point-of-care utilizing the results from this research.

The remaining authors declare that the research was conducted in the absence of any commercial or financial relationships that could be construed as a potential conflict of interest.

Copyright (c) 2019 Dwarkanath, Ponnusamy, Thomas, Joseph, Thomas, Shirley, Sheela, Mehta and Kurpad. This is an open-access article distributed under the terms of the Creative Commons Attribution License (CC BY). The use, distribution or reproduction in other forums is permitted, provided the original author(s) and the copyright owner(s) are credited and that the original publication in this journal is cited, in accordance with accepted academic practice. No use, distribution or reproduction is permitted which does not comply with these terms. 